\title{
UMA HISTÓRIA DAS INSTRUMENTALIDADES DO ESPORTE NO CAMPO DO ASSOCIATIVISMO ESPORTIVO EM PORTO ALEGRE/RS
}

\author{
A HISTORY OF THE SPORT INSTRUMENTALITIES IN THE FIELD OF \\ SPORTING ASSOCIATIONS IN PORTO ALEGRE, RS
}

UNA HISTORIA DE LAS INSTRUMENTALIDADES DEL DEPORTE EN EL ÁMBITO DEL ASOCIATIVISMO DEPORTIVO EN PORTO ALEGRE/RS

\section{Carolina Fernandes da Silva*, Janice Zarpellon Mazo *}

\section{Palavras-chave}

História. Esportes.

Associações.

Clubes.

Keywords

History. Sports.

Associations. Clubs. Historia. Deportes. Asociaciones. Clubes.
Resumo: Este artigo trata de como as instrumentalidades do esporte se modificaram no espaço do associativismo esportivo porto-alegrense do final do século XIX até meados do século XX. As fontes consultadas para a realização deste estudo, jornais e revistas, revelaram que, mais do que espaço de desenvolvimento do esporte, as associações esportivas também foram instrumentalizadas para alcançar outros objetivos, demonstrando que são mecanismos de modificação social. Desde a fundação, as associações esportivas se constituíram em espaços de instrumentalização intrínseca e/ou extrínseca do esporte.

Abstract: This article discusses how instrumentalities of sport have changed within Porto Alegre's sports associations from late nineteenth century until the mid-twentieth century. The sources - newspapers and magazines - revealed that, more than spaces for sports development, sports associations were also used to achieve other aims, showing that they are mechanisms of social change. Since their foundation, sports associations became spaces for intrinsic and/or extrinsic instrumentalization of sport.

Resumen: Este artículo revisa cómo las instrumentalidades del deporte se modificaron en el espacio del asociativismo deportivo del Porto Alegre de fines del siglo XIX hasta mediados del siglo XX. Las fuentes consultadas para la realización de este estudio, diarios y revistas, revelaron que, más que el espacio de desarrollo del deporte, las asociaciones deportivas también fueron instrumentalizadas para alcanzar otros objetivos, demostrando que son mecanismos de modificación social. Desde su fundación, las asociaciones deportivas se constituyeron como espacios instrumentalización intrínseca y/o extrínseca del deporte.
* Universidade Federal do Rio Grande do Sul. Porto Alegre, RS, Brasil. E-mail: carol_ed.fis@hotmail.com Recebido em: 29-06-2014 Aprovado em: 09-12-2014 (c) (i) () Licence 


\section{INTRODUÇÃO}

Historicamente, as associações configuraram-se nos principais espaços onde os esportes são desenvolvidos. Entretanto, para a instauração de uma associação esportiva é necessário que existam objetivos a serem alcançados, os quais podem ser externos e internos à prática esportiva. Nesta perspectiva, as associações esportivas tornam-se meios para se chegar a um fim. Assim, desde sua fundação e ao longo de sua trajetória as associações esportivas apresentaram mais de um objetivo, servindo de espaços para a instrumentalização intrínseca e/ou extrínseca do esporte.

Desde seus primeiros indícios em Porto Alegre na segunda metade do século XIX até meados do século XX, o associativismo esportivo teve diversos sentidos, inclusive 0 de originar outras associações com diferentes contornos, como o do privado e o público (MAZO et al., 2012). As formas como os pioneiros percebiam o ambiente das associações permitem a construção de diferentes representações, que se modificam com as transformações culturais e sociais ocorridas em determinados períodos históricos, marcados por continuidades e rupturas. Os fundadores e associados atribuíram ao longo do tempo diversos significados às associações esportivas, os quais estão relacionados com os desígnios atribuídos externa e internamente ao esporte.

Para Martínkóva e Parry (2012), existem objetivos externos ao esporte e é importante levá-los em consideração, uma vez que influenciam consideravelmente a sua prática. Isso acontece quando o esporte é usado instrumentalmente, isto é, como meio para atingir objetivos externos a ele, tais como fama, riqueza, a socialização, a perfeição moral, etc. Um ponto de tensionamento com relação aos objetivos externos é, em muitos casos, o entendimento acerca do esporte como tendo um valor à parte de si mesmo, e sua prática justificada com relação a valores fora de si mesmo. Por outro lado, as metas internas do esporte, como marcar um gol ou acertar uma cesta, são muitas vezes pensadas para serem intrínsecas e não instrumentais.

Entretanto Martínkóva e Parry (2012) argumentam que as metas internas do esporte também mostram uma espécie de instrumentalidade, já que o movimento humano no esporte se supõe levar a algum tipo de realização. A dupla instrumentalidade do esporte remete a alguns problemas relacionados, principalmente, com a qualidade do processo, ou seja, do próprio desempenho. Na pesquisa bibliográfica realizada para este artigo, evidenciou-se que a maioria dos autores abordou os objetivos externos ao esporte e como estes se fazem presentes; no entanto, sobre os objetivos internos existem poucos trabalhos e ainda menos abordagens sobre como os sentidos se modificaram ao longo do tempo e espaço. Nesta perspectiva, este estudo busca compreender o processo de instauração e manutenção das associações esportivas, a partir das formas pelas quais representam a instrumentalização externa e interna do esporte para e pelos grupos sociais.

De acordo com Martínkóva e Parry (2012), os níveis de instrumentalidade do esporte estão conectados com os valores compartilhados em uma determinada sociedade, e com os valores atribuídos ao esporte, que o tornam um elemento valioso para os indivíduos daquela sociedade. Porém, é no espaço do associativismo esportivo que as instrumentalidades se manifestam; o clube se tornou a unidade fundamental de estruturação, quando o esporte se organiza em entidades representativas. 
Diante dessas considerações surge o seguinte problema de pesquisa: como as instrumentalidades do esporte se modificaram no espaço do associativismo esportivo portoalegrense do final do século XIX até meados do século XX.

Inscrevendo-se nas dimensões dos estudos socioculturais, procurou-se contemplar o objetivo proposto por meio de uma coleta de informações em livros, artigos científicos, dissertações e teses. As informações foram analisadas vislumbrando-se 0 associativismo como espaço social no qual o esporte é vivenciado na sua forma extrínseca e intrínseca. Nessa direção, o esporte é tratado enquanto uma prática cultural que produz representações culturais de identidades e distinção dos grupos sociais.

Espera-se que o enfoque sobre o fenômeno do associativismo esportivo contribua para os estudos no âmbito da Sociologia Pública, pois, ao buscar uma aproximação com a sociedade, traz a comunicação e o entendimento como elementos relevantes de uma Sociologia engajada (ALMEIDA, 2014). Ruy Braga e Michael Burawoy (2009) sugerem outro papel para a Sociologia: não vista apenas enquanto ciência, mas também como moral e como força política, sendo caracterizada por um processo educativo mútuo entre o cientista e o seu público.

Todavia, a Sociologia deve conjugar o rigor da Sociologia profissional com a intervenção no espaço público e, assim, assumir a defesa dos interesses da humanidade. De tal modo que, ao analisar a instrumentalidade de mecanismos que estruturam o campo do associativismo esportivo emergem novas perspectivas para se pensar a própria História do Esporte no Brasil. Os conceitos tornam-se o instrumento dinâmico da mudança histórica e sociocultural e podem contribuir para a aproximação deste campo com a esfera pública, pois, de acordo com Almeida (2014), a Sociologia do esporte e do lazer pode trazer novos olhares à Sociologia.

\section{TECENDO CONCEITOS: ASSOCIATIVISMO ESPORTIVO}

O termo associativismo esportivo é formado por duas palavras que, juntas, ganham um novo sentido. Até mesmo essas palavras, que fornecem definição, são carregadas de representações e sentido. Associação vem do latim associare, que significa juntar, agrupar. Já o termo esportivo está relacionado a esporte, com origem no termo inglês sport, o qual, por sua vez, agregou o termo francês antigo desport, que significa "passatempo, recreação, prazer", do verbo desporter (divertir-se, distrair-se, jogar), cujo significado literal é "levar embora, retirar", o que tem o sentido de desviar os pensamentos de assuntos sérios.

Apesar de o termo esporte ter uma origem antiga, o seu significado ainda não é absoluto. Segundo o sociólogo Wilbert Marcellus Leonard (1998), o conceito de esporte significa algo diferente para cada um nós. Em busca de uma resposta para a questão "o que é esporte", Leonard (1998, p. 6) afirma: "[...] the meaning of Sport, like love, marital sucess, time, life, satisfaction, or religiosity, is self-evident until we attempt to define it unambiguously"1. No entanto, Leonard (1998) é enfático ao dizer que, academicamente, é necessária uma operação mental que permita ao cientista determinar o significado preciso dos conceitos, uma conceitualização. Ressalta, porém, que o esporte é um conceito definido de forma imprecisa.

Apesar de não termos um conceito preciso, em um trabalho científico, se faz necessário ter noções do que possa ser considerado esporte contemporaneamente, para que possamos,

1 "O significado do Esporte, como o amor, sucesso conjugal, tempo, vida, satisfação, ou religiosidade, é autoevidente até tentar defini-lo, de alguma forma, sem ambiguidades." (tradução nossa) 
a partir de um ponto de diferenciação, construir definições a propósito das práticas esportivas no passado. Diversos estudos acadêmicos (GUTTMANN, 1978; ELIAS; DUNNING, 1992; GARCIA, 2004; VIGARELLO, 2008) apresentaram elementos definidores e diferenciadores do esporte em relação a outras práticas. Nos estudos dirigidos por Corbin, Courtine e Vigarello (2008a, 2008b, 2008c) encontramos indícios de práticas corporais que foram esportivizadas em diferentes tempos e espaços sociais.

No fim do século XIX, os esportes passaram a ser vistos como práticas diferenciadas de práticas esportivas antigas e primitivas. Para Elias e Dunning (1992), há mais diferenças do que semelhanças entre os esportes modernos e os esportes tradicionais ou antigos. Para estes autores (1992), o esporte possui tempo e espaço próprios para a sua prática, além de ser "uma atividade de grupo organizada, centrada no confronto de pelo menos duas partes. Exige certo tipo específico de esforço físico e realiza-se de acordo com regras conhecidas, que definem os limites da violência que são autorizados" (ELIAS; DUNNING, 1992, p. 230).

Allen Guttmann (1978) desenvolve o conceito de esporte moderno arquitetando sete características diferenciadoras em relação aos esportes antigos e primitivos: secularização, especialização, igualdade, racionalização, burocratização, quantificação e busca por recordes. Essas características representam os atributos da sociedade moderna e apregoam a denominação de moderno ao termo esporte. A abordagem de Guttmann (1978) acerca do esporte moderno sofreu críticas "[...] por suas presunções e tendência geral funcionalista", como refere Booth (2011, p. 5), além disso, "[...] também incorpora a homogeneização de diferentes sociedades, incluindo seus esportes, as quais ele deduz que sigam um modelo ocidental", ou seja, pouco considerou no seu enfoque as dimensões de espaço, tempo e cultura.

Para Martínkóva e Parry (2012), esportes são competições governadas por regras, nas quais as habilidades físicas são contestadas. Tem caráter mais formal, sério, competitivo, organizado e institucionalizado do que os jogos a partir dos quais muitas vezes eles surgiram. O objetivo do esporte é conseguir algo, cumprir uma tarefa que é dada por regras acordadas. $E$, justamente, é a tensão causada pela busca do melhor desempenho no que diz respeito a uma determinada tarefa, em conjunto e ao mesmo tempo contra um adversário, que forma a base do esporte.

Os sentidos do esporte também são modificados pela tecnologia aplicada neste campo. Um exemplo é o caso da prática do remo no Rio Grande do Sul. Havia competições em áreas fluviais com barcos que necessitavam de pás de remo para o deslocamento. Assim, principalmente em meados do século XIX, a prática do remo era definida no momento que existia o movimento de remar aliado a uma disputa entre duas ou mais embarcações e regras predefinidas. Já no fim do século XIX, para haver competições de remo era preciso ter barcos apropriados para o esporte, importados do exterior, denominados gigs ${ }^{2}$ (AMARO JÚNIOR, 1942, p. 43). No entanto, já havia no Rio Grande do Sul regatas comemorativas com barcos chamados escaleres, isto é, embarcação a remo e a vela, ou barcos de pescadores, e não gigs (REGATAS, 1894).

Essa representação de como praticar o esporte vai ao encontro da afirmativa de Burke (2009), de que todas as formas culturais são invenções. Todavia a liberdade, criatividade e invenção têm limites e são moldadas por restrições culturais, bem como sociais e materiais. Deste modo, Burke (2009) recomenda que se fale em reconstrução de tradições "mais do que

2 Denominação utilizada para barcos usados especialmente na prática do remo. 
invenção, uma vez que o que acontece não é criação a partir do nada, mas uma tentativa de bricolagem, de colocar material velho em novos usos ou de fazer novas declarações a partir de velhas palavras" (BURKE, 2009, p. 157-158). O associativismo esportivo teuto-brasileiro em várias cidades do Rio Grande do Sul é um caso que exemplifica a reconstrução de tradições pelos imigrantes alemães na segunda metade do século XIX.

Para Chartier (2002), as representações mentais e as práticas sociais são sempre governadas por mecanismos e dependências desconhecidos dos próprios sujeitos. Por isso a necessidade de interpretá-las e analisá-las para compreender o mundo criado por esses agentes sociais e pelo fato das representações terem o poder de modificar a realidade que parecem refletir (BURKE, 2005). Desta forma, as representações construídas em torno das associações esportivas fornecem sentidos que, por vezes, são desconhecidos pelos próprios sujeitos. Para Pesavento (2008, p. 39), "indivíduos e grupos dão sentido ao mundo por meio das representações que constroem sobre a realidade".

As representações são matrizes geradoras de condutas e práticas sociais dotadas de forma integradora, coesiva e explicativa de uma realidade; elas são portadoras do simbólico e dizem mais do que aquilo que demonstram ou ocultam. Desta forma, sua força está na capacidade de mobilização e legitimidade social. Pesavento (2008, p. 41) afirma que "[...] 0 grupo, que tem o poder simbólico de dizer e fazer crer sobre o mundo tem o controle da vida social", portanto, as representações identitárias podem ser utilizadas para jogos de poder.

\section{OS SENTIDOS DO ASSOCIATIVISMO ESPORTIVO}

Segundo o sociólogo Raymund Boudon (1990), o termo associação apresenta um sentido amplo e outro restrito. Em seu sentido amplo designa todo e qualquer agrupamento, seja qual for a sua forma jurídica e a sua finalidade. E, em seu sentido restrito, o termo designa um agrupamento de duas ou várias pessoas que põem em comum, de maneira permanente, os seus conhecimentos e as suas atividades numa finalidade que não seja a de partilhar lucros. O sentido amplo do termo abrange demasiada gama de agrupamentos, incluindo aqueles que não têm registros oficiais e sem uma estrutura para localização e armazenamento de materiais, assim como não diferencia os significados atribuídos pelos homens em determinados locais e períodos.

A organização de associações esportivas tem a prática de esporte(s) como 0 objetivo em comum deste agrupamento voluntário (LÜSCHEN; SAGE, 1981). Porém, em torno desse objetivo existe a oportunidade de construção e negociação de representações que identificam e diferenciam os grupos sociais. No caso do Turnen, desenvolvido na Alemanha, no final do século XVIII e início do século XIX, por Friedrich Jahn, essa prática operou na consolidação de um sentimento coletivo para a constituição do Estado Alemão.,4

Logo, no Brasil, em particular no estado do Rio Grande do Sul, o Turnen adotado em escolas e sociedades de ginástica expressou um conjunto de práticas e representações culturais que contribuíram para a preservação de identidades dos imigrantes alemães e seus descendentes (KILPP, 2012; MAZO, 2003; TESCHE, 1996). Outras pesquisas (SILVA; MAZO,

3 Conforme Hobsbawm e Ranger (1984, p. 311) "[...] o alinhamento das associações de ginástica à idéia de nação alemã vitoriosa manifestouse simbolicamente, quando a maioria das associações de ginástica assumiram as novas cores da nação alemã — 0 preto, o vermelho e 0 branco".

4 Para Norbert Elias (1997, p. 140), a força da crença na comunidade nacional é "[...] uma das mais poderosas, talvez a mais poderosa das crenças sociais dos séculos XIX e XX". 
2009; SILVA, 2011; MAZO; FROSI, 2012; SILVA, PEREIRA, MAZO, 2012; SILVA; MAZO, 2014) analisaram a instauração de associações esportivas, em diferentes períodos históricos, enquanto estratégias de construção de identidades culturais ligadas a imigrantes europeus e seus descendentes. Esses estudos reconhecem a utilização de associações esportivas como instrumentos de estabelecimento de fronteiras de identidades entre culturas, bem como as práticas esportivas adotadas e distinguidas a determinados grupos.

Até o princípio do século XX, as associações esportivas demarcavam um espaço sociocultural no Rio Grande do Sul. Durante um longo período, o associativismo esportivo desempenhou papel central na expressão das identidades culturais dos imigrantes e seus descendentes nas cidades marcadas pela presença de grupos advindos de diferentes países da Europa, que buscaram perpetuar hábitos, práticas e costumes de origem. Com este sentido o associativismo esportivo perdurou fortemente até aproximadamente o fim da década de 1910, quando algumas associações esportivas adotaram representações identitárias brasileiras, em um processo de nacionalização iniciado durante a 1a Guerra Mundial e acentuado na 2ª Guerra Mundial (MAZO, 2007, SILVA, 2011). Essas alterações foram absorvidas pelas associações, como ocorreu com os clubes de remo fundados pelos imigrantes alemães que trocaram sua denominação do alemão para a língua portuguesa (FRISCH-AUF, 1917) ${ }^{5}$, entre outras mudanças.

Assim, quando a diferenciação entre imigrantes teve um início de diluição, as associações esportivas procuraram formar outro sentido. Segundo o historiador Peter Burke (2009), os clubes, que são versões de associações, deram uma importante contribuição ao processo de modernização e foram particularmente importantes nos séculos XVIII e XIX. Além disso, buscaram estratégias de integração entre grupos de imigrantes, como ocorreu em Londres entre os séculos XVI e XVIII (BURKE, 2009) e em Porto Alegre a partir de meados do século XIX (MAZO, 2003). Neste período, em alguns países os clubes eram utilizados como instrumentos de distinção social, enquanto que no Rio Grande do Sul esta forma de organização esportiva trazida principalmente pelos imigrantes alemães, além de promover a socialização, foi também uma estratégia de manutenção da identidade etnocultural.

\section{ASSOCIATIVISMO ESPORTIVO: ESPAÇOS DE INSTRUMENTALIZAÇÃO DO ESPORTE}

No estudo feito pelo etnólogo Allen Guttmann (1978), o esporte é um fenômeno cultural presente em distintas épocas históricas e nas mais variadas civilizações. Para tanto, qualifica o esporte moderno como uma forma singular de competição física não utilitária, que nasceu na Inglaterra e se difundiu para os Estados Unidos e para a Europa Ocidental. Posteriormente, o esporte se espalhou pelo restante do mundo.

As práticas esportivas institucionalizadas nos clubes em quase todo o mundo seguiram 0 modelo inglês. $O$ esporte era, inicialmente, um costume restrito à aristocracia inglesa, a qual assegurou sua perpetuação na instituição escolar (THOMAS; HAUMONT; LEVET, 1988; ELIAS; DUNNING, 1992; WALVIN 1994). Os primeiros clubes esportivos organizados na Inglaterra no século XVIII tinham como objetivos a fixação das regras dos jogos praticados e 0 controle da procedência social dos jogadores. 
O desenvolvimento do esporte para além do espaço escolar foi realizado pelos alunos egressos das escolas inglesas, através da fundação de clubes e ligas esportivas. Esse esporte se caracterizava como uma prática educativa, lúdica e de distinção social (MARIVOET, 1998, p. 16). Para Bourdieu (1979), o esporte é uma das práticas capazes de distinguir socialmente os agentes conforme a sua participação.

A distinção foi iniciada no modelo clubístico inglês e restaurada nos clubes disseminados pelo mundo que seguiam este modelo. $O$ processo de institucionalização e expansão do modelo esportivo inglês compreende o período do final do século XIX e início do século XX. A difusão das práticas esportivas ocorreu pela multiplicação dos clubes de futebol, juntamente com a progressiva unificação das regras. Os clubes de futebol ingleses evoluíram no período compreendido entre 1840 e 1913, tornando-se representativos no modelo de organização da prática esportiva contemporânea. 0 modelo organizacional do futebol foi adotado para a estruturação do atletismo, natação e tênis pela burguesia e a classe média urbana inglesa. A prática e a ideologia da organização esportiva visavam basicamente romper a cultura aristocrática.

O esporte moderno institucionalizado nos clubes e associações, a partir de 1870, constituiu-se em uma "tradição inventada" (HOBSBAWN; RANGER, 1984, p. 9) pelo Estado e grupos sociais específicos como resposta às turbulentas modificações sociais. Segundo Hobsbawn e Ranger $(1984$, p. 9) uma tradição inventada é:

[...] um conjunto de práticas, normalmente reguladas por regras tácita ou abertamente aceitas; tais práticas, de natureza ritual ou simbólica, visam inculcar certos valores e normas de comportamento através da repetição, o que implica, automaticamente, uma continuidade em relação ao passado.

As bases do modelo esportivo clubístico inglês expandiram-se para o mundo e foram apropriadas segundo características sociais e culturais. Thomas, Haumont e Level (1988) relacionam o caso da ginástica e do futebol na Rússia, primeiramente organizados em clubes, posteriormente agrupados em federações e depois a integração dos clubes nos sindicatos. $\mathrm{Na}$ Finlândia, a reação nacional e popular à adoção do modelo de clube inglês pela burguesia de origem sueca conduziu à organização de associações e federações polidesportivas, no final do século XIX. Na França, depois da derrota de 1870, também se criou um grande número de sociedades voltadas à preparação física e militar. 0 modelo esportivo inglês adquiriu uma posição hegemônica na França somente depois da 1ª Guerra Mundial (1914-1918) e se manteve até aproximadamente os anos de 1970. A penetração do esporte nesse país é explicada pelo nacionalismo e pela intervenção do Estado no sistema esportivo francês (THOMAS; HAUMONT; LEVEL, 1988).

Santos e Montalvo (1995) constataram a escassa participação dos espanhóis em todo tipo de associação, inclusive esportiva. A imagem negativa do associativismo esportivo na Espanha é justificada pelo funcionamento de outras formas associativas, como manifestações e festas populares, que do mesmo modo desenvolvem sentimentos de comunidade e afirmação de identidades (PÉREZ DIAZ, 1996).

O estudo comparativo de Klaus Heinemann et al (1997) mostra que na Alemanha existe uma estrutura de clubes rica em relação à Espanha. Na Alemanha, a evolução do modelo esportivo inglês foi modificada pela tradição nacional do Turnen. Embora conhecido pela denominação de ginástica, o movimento do Turnen incorporava diversos exercícios físicos 
e práticas esportivas com fins sociais e políticos. Segundo Tesche (1996, p. 35), a ginástica de Jahn "[...] está intimamente ligada à ideia de arregimentar o povo na luta contra Napoleão. Os exercícios de ginástica subordinam-se à finalidade de preparo militar e à educação da consciência de ser um povo alemão". Nesta perspectiva, a ginástica com rígidos princípios de disciplina, obediência e dedicação era um instrumento de ação moral e política na educação da juventude.

Para além da construção de identidades etnoculturais e busca de distinção social, o processo de estabelecimento dos esportes no estado do Rio Grande do Sul ocorreu em conjugado com a busca da modernização em alguns setores da vida dos sul-rio-grandenses. A busca pela modernidade demanda um rompimento com o passado e com as suas tradições, como nos esclarece Giddens (2000, p. 73): "[...] a modernidade é muitíssimo mais dinâmica do que qualquer tipo de ordem social preexistente, em uma sociedade - mais precisamente, um complexo de instituições sociais - que, à diferença de todas as culturas anteriores, vive no futuro e não no passado".

A modernização da capital do estado foi marcante a partir da década de 1920 (MONTEIRO, 1995). Conforme o autor (1995), em Porto Alegre, a modernidade fluía vertiginosa e gloriosa, demolia casas, hábitos e costumes do passado, além de imprimir um modo de ser moderno. Tal movimento alcançou as associações esportivas, que também buscaram formas de fazer parte do processo de modernização, dentre estas, a adoção de novos esportes. Como assinala Pereira (2012), o turfe tem suas representações ligadas a uma sociedade patriarcal predominantemente rural, onde a força e a capacidade concentram-se no animal, já o hipismo incorpora representações mais ligadas ao desempenho do ser humano também, o que está em consonância com um contexto de modernização.

Outro esporte surgido em um período de modernização da cidade e utilizado para distinção social foi o golfe. O primeiro clube de golfe foi o Porto Alegre Country Club (PACC), no início da década de 1930, pela iniciativa de médicos e empresários porto-alegrenses. Nessa associação esportiva, a presença de nomes reconhecidos no cenário político e econômico reforçava a imagem do clube enquanto um espaço de distinção social em Porto Alegre (PEREIRA; FERNÁNDEZ; MAZO, 2010). Os exemplos citados assinalam que o associativismo esportivo, além de ser uma estrutura de sociabilidade entre indivíduos que se interessam por esporte, é um ambiente onde se dá sentido ao mundo por meio de representações construídas e expressas neste local, sejam de identidade etnocultural, de distinção social ou, até mesmo, de inserção em uma representação de modernidade.

A alteração da fisionomia da capital do estado por meio de intervenções urbanas, como a destinação de espaços públicos às atividades de lazer para a população, também é decorrente da modernidade. O planejamento urbano, obras de saneamento, alargamento de ruas, embelezamento da cidade, construção de prédios públicos e de praças e parques tornou-se uma preocupação do governo municipal. Destaca-se a construção de praças e a apropriação destes espaços públicos para fins de lazer, promovendo práticas corporais e esportivas, organizadas à semelhança das que eram desenvolvidas nos clubes esportivos (OLIVEIRA; MAZO; STIGGER, 2010).

De acordo com Oliveira, Mazo e Stigger (2010), o surgimento das primeiras praças públicas em Porto Alegre foi no final do século XIX, entretanto, somente no início do século XX começou, gradualmente, a ocupação destes espaços pelos porto-alegrenses para a 
sociabilidade e lazer. Em decorrência das mudanças ocasionadas pela Revolução Industrial, houve a disseminação da prática dos lazeres em um quadro ocidental, no qual as diversas camadas sociais passaram a usar, em escala cada vez mais alargada, o tempo livre em práticas culturais. Esta apropriação oportunizou a emergência de outras formas de lazer pela população, como as práticas corporais e esportivas, nas praças públicas que, inicialmente, eram destinadas apenas aos passeios dos porto-alegrenses.

Desta forma, a direção das ações nos espaços das praças aparece como função inerente à municipalidade. Nesse sentido, foi instituído o "Serviço de Recreação Pública" pela Prefeitura Municipal de Porto Alegre, em 1926. Este setor foi idealizado pelo Prof. Frederico Guilherme Gaelzer, o primeiro inspetor de Educação Física da Diretoria Geral da Instrução Pública do Estado do Rio Grande do Sul, que antes disso estudou em uma ACM dos Estados Unidos. É considerado o pioneiro na institucionalização da recreação pública na cidade de Porto Alegre (FEIX, 2003; MACEDO, 1973), pois implantou os Jardins de Recreio, também chamados de Praças de Recreio. Mais tarde organizou as Praças de Desportos, também denominadas Praças de Educação Física, em razão do crescimento de práticas esportivas nas quadras de esportes arquitetadas nestes locais.

Em uma reportagem específica sobre as Praças de Desportos/Educação Física na Revista do Globo, em 11 de Setembro de 1937 (MAZO, 2004), foi ressaltada a importância da recreação pública gratuita como parte integrante na vida dos povos civilizados. Além disso, no texto foi ponderado que a Praça de Educação Física, funcionando ao lado da escola, a qual era considerada elemento indispensável, servia, nas horas em que esta não funcionava, como centro de recreação pública da juventude e ponto de reunião social de adultos do bairro. Assim as praças tornaram-se os espaços para o tempo livre da população em geral, mas, principalmente, daqueles que não tinham acesso às associações esportivas, instauradas para a parcela da população que tinha condições financeiras de pagar a mensalidade. Os candidatos a sócios de clubes passavam pela aprovação da diretoria, que analisava a proposta e a representação do indivíduo na sociedade porto-alegrense.

Conforme Oliveira e Mazo (2010), as associações esportivas porto-alegrenses eram restritas a uma elite social e não consentiam 0 acesso às classes menos favorecidas economicamente. Sendo assim, a praça tornou-se para alguns grupos sociais o único espaço possível para a prática esportiva. Nas Praças de Desportos/Educação Física, desencadeouse a formação de equipes esportivas, as quais representavam as praças nas competições citadinas (OLIVEIRA; MAZO, 2010). Então, os clubes das praças surgiram do padrão social e cultural do associativismo esportivo de então e abonaram um novo sentido ao conceito, pois formaram expressões associativas onde a instrumentalidade intrínseca do esporte tinha destaque.

\section{CONSIDERAÇÕES FINAIS}

Os esportes estavam presentes no espaço do associativismo esportivo, para além do seu objetivo final, o da prática em si, mas como instrumento para se chegar a objetivos externos, como representações de modernidade, de identidade etnocultural e de distinção. Percebeu-se que 0 associativismo esportivo tinha sua instrumentalidade, pois gerava as próprias representações e novas práticas, no momento em que as suas propriedades eram 
manipuladas. Neste cenário adquiriu novos sentidos com: mudanças nas denominações; espaços sendo compartilhados por diferentes grupos; criação de novos clubes pelas esferas públicas; sedes com nova localização; entre outros.

O associativismo esportivo se constitui não apenas em um meio para o desenvolvimento do esporte, mas é parte da construção do conceito de esporte e uma ferramenta para a instrumentalização do esporte, para se chegar a fins externos à prática, propiciando modificação social. Como este estudo está situado em um recorte temporal e espacial, abre-se a possibilidade para estudos futuros em diferentes períodos, para além da primeira metade do século $X X$, buscando a comparação de resultados, semelhanças e diferenças, e, assim, possibilitar a construção de conceitos aplicáveis de maneira ampla.

Novas perspectivas também podem ser utilizadas para estudar o objeto, associativismo esportivo, de maneira a aproximá-lo ainda mais da esfera pública, como, por exemplo, como os clubes esportivos se implantaram e disseminaram pelos diversos estados brasileiros, e, nestes contextos, identificar como contribuíram para a construção de culturas específicas, e abordar as diferenças ocorridas em cada processo, correlacionando-as. Assim, será possível aproximar a História do Esporte no Brasil das ideias de Braga e Burawoy (2009), comunicá-la com a Sociologia Pública, permitindo aos brasileiros conhecer mais sobre o seu passado, assim como a construção da atualidade, e percorrer caminhos que, ao analisá-los, nos é permitido repeti-los ou não.

\section{REFERÊNCIAS}

ALMEIDA, Marco Antonio Bettine. As reflexões sobre o esporte e o lazer: via esfera pública. In: CONGRESSO BRASILEIRO DE HISTÓRIA DO ESPORTE, LAZER E EDUCAÇÃO FÍSICA, 13. 2014, Londrina. Anais... Londrina: Universidade Federal de Londrina-Paraná, 2014. p. 572-578.

AMARO JÚNIOR. Almanaque Esportivo do Rio Grande do Sul. Porto Alegre: Tipografia Esperança, 1942.

BOUDON, Raymond. Dicionário de sociologia. Lisboa: Publicações Dom Quixote, 1990.

BOURDIEU, Pierre. O habitus e o espaço dos estilos de vida. In: A DISTINÇÃO: crítica social do julgamento. Tradução de Daniela Kern; Guilherme J. F. Teixeira. São Paulo, Porto Alegre, Edusp; Zouk, 1979. p. 165-180.

BOOTH, Douglas. História do Esporte: abordagens em mutação. Recorde: Revista de História do Esporte, Rio de Janeiro, v.4, n. 1, p. 1-40, junho de 2011.

BRAGA. Rui; BURAWOY, Michael (Org.). Por uma sociologia pública. São Paulo: Alameda, 2009.

BURKE, Peter. 0 que é história cultural? Rio de Janeiro: Jorge Zahar, 2005.

BURKE, Peter. O historiador como colunista. São Paulo: Civilização Brasileira, 2009.

CHARTIER, Roger. A História Cultural: entre práticas e representações. Lisboa: Difel, 2002.

CORBIN, Alain; COURTINE, Jean-Jacques; VIGARELLO, Georges. História do corpo. 
CORBIN, Alain; COURTINE, Jean-Jacques; VIGARELLO, Georges. História do corpo.

Petrópolis, RJ: Vozes, 2008b. v. 2: Da Revolução à Grande Guerra.

CORBIN, Alain; COURTINE, Jean-Jacques; VIGARELLO, Georges. História do corpo.

Petrópolis, RJ: Vozes, 2008c. v.3: As mutações do olhar: o século XX.

ELIAS, Norbert; DUNNING, Eric. A busca da excitação. Lisboa, Difel, 1992.

ELIAS, Norbert. Os alemães: a luta pelo poder e a evolução do habitus nos séculos XIX e XX.

Trad. Álvaro Cabral. Rio de Janeiro: Jorge Zahar, 1997.

FEIX, Eneida. Lazer e cidade na Porto Alegre do início do século XX: institucionalização da recreação pública. 2003.108 f. Dissertação (Mestrado em Ciências do Movimento Humano) Universidade Federal do Rio Grande do Sul, Escola de Educação Física, Porto Alegre, 2003.

GARCIA, Rui. Antropologia do desporto: o reencontro com Hermes. Revista Povos e Culturas, Lisboa, n. 9, p. 205-224, 2004.

GIDDENS, Anthony. As conseqüências da modernidade. São Paulo: UNESP, 1991.

GUTTMANN, Allen. From ritual to record: the nature of modern sports. New York: Columbia University, 1978.

HEINEMANN, Klaus et al. Clubs deportivos en España y Alemania: una comparación teórica y empírica. Apunts Educació Fisica i sports, Barcelona, n. 49, 3.trim. 1997. Disponível em: < http://www.revista-apunts.com/es/hemeroteca?article=715 >. Acesso em: 22 abr. 2014.

HOBSBAWN, Eric; RANGER, Terence (Org.). A invenção das tradições. 2. ed. Rio de Janeiro: Paz e Terra, 1984.

KILPP, Cecília Elisa. O Turnen e o esporte nas associações teuto-brasileiras de Estrela/ Rio Grande do Sul. 2012. 97 f. Dissertação (Mestrado em Ciências do Movimento Humano) Universidade Federal do Rio Grande do Sul, Escola de Educação Física, Porto Alegre, 2012.

LEONARD, Wilbert Marcellus. Sociological perspective of sport. Boston: Allyn and Bacon, 1998.

LÜSCHEN, Günter; SAGE, George. (Ed.). Handbook of social science of sport. Champaign, Illinois: Stipes, 1981.

MACEDO, Francisco Rio-pardense de. Porto Alegre, história e vida da cidade. Porto Alegre: Editora da Universidade/UFRGS, 1973.

MARIVOET, Salomé. Aspectos sociológicos do desporto. Lisboa: Horizonte, 1998.

MARTÍNKOVÁ, Irena; PARRY, Jim. The double instrumentality of sport. Studies in Physical Culture and Tourism, Poznan (Polônia), v. 18, n. 1, p. 25-32, 2011.

MAZO, Janice. Emergência e a expansão do associativismo desportivo em Porto Alegre (1867-1945): espaço de representação da identidade cultural teuto-brasileira. 2003. 365 f. Tese (Doutorado) - Universidade do Porto. Faculdade de Educação Física e Ciências do Desporto, Porto, 2003.

MAZO, Janice. Catálogo do esporte e da educação física na Revista do Globo (1929-1967). Porto Alegre: PUCRS, 2004. 1 CD-ROM. 
MAZO, Janice. A nacionalização das associações esportivas em Porto Alegre (1937-1945). Movimento, Porto Alegre, v. 13, n. 3, p. 43-63, 2007.

MAZO, Janice; FROSI, Tiago. Em busca da identidade luso-brasileira no Associativismo esportivo em Porto alegre no princípio do século XX. Revista do Colégio Brasileiro de Ciências do Esporte, Florianópolis, v. 3, n. 2, p. 57-72, 2009.

MAZO, Janice et al. Associações Esportivas no Rio Grande do Sul: lugares e memórias. Novo Hamburgo: FEEVALE, 2012. 1 CD-ROM.

MONTEIRO, Charles. Porto Alegre: urbanização e modernidade, a construção social do espaço urbano. Porto Alegre: EDIPUCRS, 1995.

OLIVEIRA, Maria Luiza; MAZO, Janice. A criação dos clubs nas praças públicas da cidade de Porto Alegre: 1920-1940. Revista Brasileira de Ciências do Esporte, Campinas, v. 32, n. 2, p. 123-139, dez. 2010.

OLIVEIRA, Maria Luiza; MAZO, Janice; STIGGER, Marco Paulo. A organização das Praças de Desporto/Educação Fisica da cidade de Porto Alegre: 1920-1940. Licere, Belo Horizonte, v. 13, n. 1, p. 1-33, mar. 2010.

PEREIRA, Ester; FERNÁNDEZ, Elias; MAZO, Janice. A Fundação do Primeiro Clube de Golfe em Porto Alegre. Cinergis, Santa Cruz do Sul, v. 11, n. 2, p. 27-34, jul./dez. 2010.

PEREIRA, Ester. As práticas equestres em Porto Alegre: percorrendo o processo da esportivização. 2012. 156 f. Dissertação (Mestrado em Ciências do Movimento Humano) Universidade Federal do Rio Grande do Sul. Escola de Educação Física, Porto Alegre, 2012.

PÉREZ-DÍAZ, Victor. La démocratie espagnole vingt ans aprés. París: Compléxe, 1996.

PESAVENTO, Sandra. História \& História Cultural. 2. ed. Belo Horizonte: Autêntica, 2008.

REGATAS. Jornal do Commércio, Porto Alegre, 15 set. 1894.

SANTOS, Francisco; MONTALVO, Antônio. El asociacionismo deportivo. Madrid: Consejo Superior de Deportes, 1995.

SILVA, Carolina; MAZO, Janice. Grêmio de Regatas Almirante Tamandaré: memórias da fundação do primeiro clube de remo "brasileiro" em Porto Alegre (1903-1923). Arquivos em Movimento, Rio de Janeiro, v. 5, n. 2, p. 109-129, jul./dez. 2009.

SILVA, Carolina. 0 remo e a história de Porto Alegre: mosaico de identidades culturais. 2011.151f. Dissertação (Mestrado em Ciências do Movimento Humano) - Universidade Federal do Rio Grande do Sul. Escola de Educação Física. Porto Alegre, 2011.

SILVA, Carolina; PEREIRA, Ester ; MAZO, Janice. Clubes sociais: práticas esportivas e identidades culturais. Licere, Belo Horizonte, v. 15, p. 1-21, 2012.

SILVA, Carolina; MAZO, Janice. Grêmio de Regatas Almirante Tamandaré: uma ameaça ao império identitário teuto-brasileiro no cenário do remo porto-alegrense. Movimento, Porto Alegre, v. 20, n.1, p. 59-69, 2014.

TESCHE, Leomar. A prática do turnen entre os imigrantes alemães e seus descendentes no RS: 1867-1942. ljuí: Editora da UNIJUÍ, 1996. 
THOMAS, Raymond; HAUMONT, Antoine; LEVET, Jean Louis. Sociologia del deporte.

Barcelona: Bellaterra, 1988.

VIGARELLO, Georges. História do corpo. Petrópolis, RJ: Vozes, 2008.

WALVIN, James. The people's game the history of football revisited. London: Mains, 1994. 